
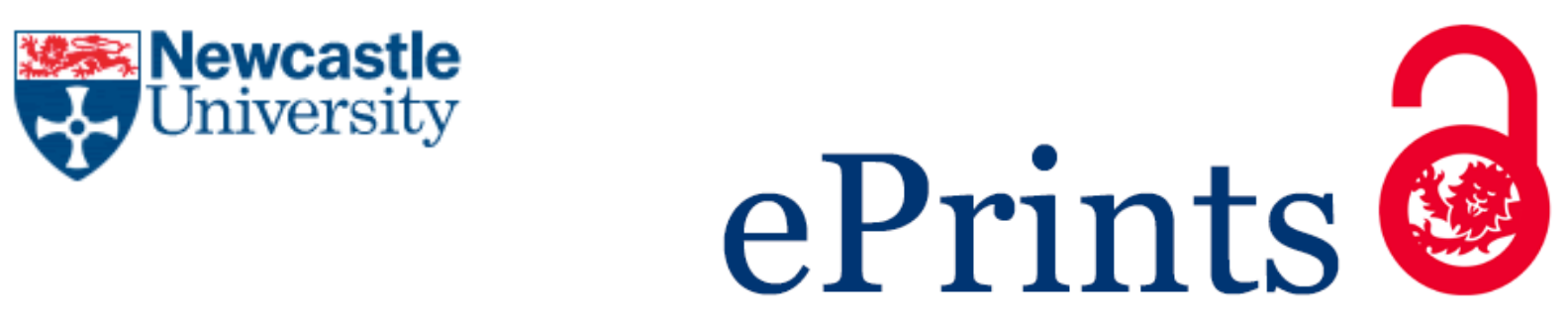

Woods S. Why we should save the anthropocentric person. In: Coggon, J; Kushner, T; Holm, S; Chan, S, ed. From Reason to Practice in Bioethics: An anthology dedicated to the work of John Harris. Manchester, UK: Manchester Univerity Press, 2015, pp.102-118.

\title{
Copyright:
}

(c) Manchester Univerity Press, 2015.

Link to volume:

http://www.manchesteruniversitypress.co.uk/cgi-bin/indexer?product=9780719096235

Date deposited:

$15 / 02 / 2016$

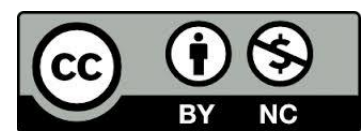

This work is licensed under a Creative Commons Attribution-NonCommercial 3.0 Unported License 


\section{Why we should save the anthropocentric person.}

\section{Simon Woods}

Key words: person, neonate, embryo, anthropocentric, Levinas, Wittgenstein, moral status, gradualism, aliens, animals.

Simon Woods is a senior lecturer and Co-Director of the Policy, Ethics and Life Sciences Research Institute (PEALS), University of Newcastle (UK). PEALS is an interdisciplinary bioethics research centre involved in research teaching and outreach on the ethical and social implications of the life sciences.

\section{Moral foundations.}

In order to 'do' ethics we need to have an account of the kinds of thing that matter; morally speaking. This is surely the preeminent question for moral philosophers, and John Harris's introduction to medical ethics, The Value of Life (1985) ${ }^{1}$ (hence TVOL) is no exception since it begins by addressing the very point. Looking back over the thirty odd years in which the book has been around it is clear that the approach was fresh, provocative, broadly coherent and had much to say about contemporary issues at the same time as horizon scanning for the burgeoning concerns related to developments in genetics, biotechnology, and reproductive therapies. The book, or rather John Harris's approach, did much to forge virgin ground for the then comparatively new field of medical ethics and for bioethics more broadly. Since then John Harris has continued to address the agenda first set out in TVOL with an often controversial take on contemporary issues within medicine and with a forthright and forward facing approach to the boundary breaking biosciences. However the one matter that has not been revisited 
to any satisfaction is the underpinning and more theoretical aspect of the Harris position, the concept of the person which lies beneath his account of the 'valuable life'.

In this essay I will set out what I understand to be Harris's take on the 'person' and then turn to some concerns about the approach, not with 'knock down' arguments but more as commentary and to indicate points of irritation, itches where the urge to scratch remains unsatisfied. Space does not permit a robust alternative view, but I shall give some indication of where and why there is still important work to be done. A main point I will argue is for the retention an anthropomorphic account of the person.

Many philosophical approaches to ethics are foundationalist; seeking to find the ground, the first premise, on which the edifice can be constructed. John Harris's approach is no exception and the foundation for his work is the concept of the person. Harris's notion of the person is not to be confused with the ordinary usage of the term; in his work it is used in a deliberately stipulative and technical way. For Harris 'person' has a particular meaning and so I shall adopt the practice of italicizing the term in this essay whenever I use the term in Harris's sense as defined in the following passage:

In identifying the things that make human life valuable we will be pointing to the features that would make the existence of any being who possessed them valuable. It is important to have a word for such beings which is not simply anthropocentric or species-specific. I shall use the term person to stand for any being who has what it takes to be valuable in the sense described, whatever they are otherwise like. ${ }^{2}$

In this essay I shall develop a number of thoughts to explore why Harris's stipulation of person is both abstract and idealized to the point that it excludes what we have reason to 
consider as falling within our moral concern. The claims I will make about the limitations of Harris's work could (and have) been applied to other proponents of a certain kind of philosophical bioethics ${ }^{345}$ who all claim rather too much for what such approaches can achieve. Despite protestations that margins of doubt will be respected, and cautionary erring will be adjusted for, the net result of Harris's arguments are still pretty precise in their implications, claiming to resolve or dissolve certain moral problems with a precision that cannot be sustained. The force of his arguments also carries the implication that they should be followed through to their logical end which often leaves one faced with conclusions that are too far out of line with everyday morality. In addition I shall argue that the 'self-valuing' criterion is just not plausible without some further and more subtly complex account of how a person achieves that status.

\section{Harris's theory of the person.}

The foundationalist approach sees the starting task of a moral theory as delineating those things that have moral worth, or to use Harris's term, those things that have value, from those that do not. Unless we are able to make this basic discrimination ethics is impossible. However, this isn't the whole picture. For ethics to 'get going', so to speak, there needs to be at least two kinds of entity, moral agents, agents with the capacity for volitional action such that it makes sense to talk of their having responsibility for their actions; to judge them worthy of praise or blame. In addition there must be entities that have moral worth, that have the right to be cared about and considered in the deliberations of moral agents. Moral agents of course have moral worth but this does not exhaust the moral domain since there are many entities that are not moral agents yet they 
do merit the care and consideration of moral agents. The point can be developed in a prosaic way by considering the difference between the act of kicking a stone and the act of kicking a cat. It seems reasonable to say that the only harm done in kicking a stone is potentially to the kicker's toe since one conception of whether a thing can be harmed or not is linked to whether that thing is both alive and is sentient. A stone, being nonsentient, is not the sort of thing that can be hurt, but what of a cat? Presuming that the kick causes the cat pain then the cat is hurt but we can only begin to talk of pains inflicted as wrongs when the kicker is the sort of thing that can do wrong. A judgement regarding the cat's status will rest on its capacity to both feel pain and to be wronged. An evaluation of the kick will rest on the capacity of the kicker both to inflict pain and do wrong. Ethics requires that there exist entities capable of doing wrong and plausibly, things that can be wronged.

Therefore a necessary condition for ethics, and hence for morality of any kind is that there are beings with the capacity for agency, that is with the capacity for acting on the basis of reasons, since agency of this kind is necessary before we can talk of moral responsibility. I would also add an additional point, since my prosaic example is itself rather abstract. To be a moral agent is not to have certain kinds of 'internal' mental states, since the stuff of morals is not internal but social. So I would add that we can only make sense of a moral agent from within a moral community and moreover the human community is just such an example.

While it may seem reasonable to claim that the highest moral worth attaches to moral agents the concept of the moral agent does not exhaust the category of things worthy of moral concern. Though I agree with Harris that at least some human beings are also moral 
agents, where we differ is that for Harris not all human beings justify our moral concern and for me they do.

John Harris wrote TVOL shortly after the establishment of the Committee of Inquiry into Human Fertilisation and Embryology, the so-called 'Warnock Committee'. ${ }^{6}$ This government committee was commissioned to inquire into the ethical implications of artificial reproduction and related research. Discussion inevitably focussed on the moral status of the human embryo, and within these, advocates of traditional moral positions, such as the Catholic Church inevitably defended the status of the embryo as inviolable. However the issues were also aired in more secular terms and Mary Warnock, philosopher and chair of the committee argued that:

'Human' is a biological term, and simply distinguishes humans from other animals. And it seems to me of paramount importance that we, being human should recognise that there are ways of treating our fellow humans that are right and other ways that are wrong. This is a moral principle, the very principle, in fact, upon which the demand for rights depends. ${ }^{7}$

By this Warnock implies that by being human we necessarily partake of a moral domain but the thought is underdeveloped; and Harris is right to pick up on it. As an acknowledged supporter of in vitro fertilisation and embryo research ${ }^{8}$ Harris rejects this view and denies that there is any necessary connection between being human and having moral status. Harris attacks the notion of resemblance, denying the moral significance of resemblance at the level of biology (Warnock's claim) or because of resemblance in appearance as for example, argued by the developmental biologist Clifford Grobstein. Grobstein claims that the threshold of moral significance for the developing embryo is 
when it becomes 'recognizable as human', conveniently, as Harris implies, at the end of the first trimester, the traditional biological transition point of embryo to fetus. ${ }^{10}$ Harris dismisses these biological approaches as 'species prejudice, arbitrary but understandable. ${ }^{11}$ However Harris does endorse resemblance of another kind; that things of moral status resemble one another in the possession of certain kinds of intellectual property. So for Harris it doesn't matter what a person looks like so long as they are capable of instantiating certain mental properties, including the property of self-valuing. However contra Harris, I would suggest that the moral significance of the human, the anthropocentric criterion, ought to be treated a little more generously as, albeit an imperfect, attempt to struggle with a profound ethical problem. One can appreciate the temptation to seek a secular ground for the moral status of the embryo in biological terms as there was a need to begin to deal with the ethical concerns that embryo research raised at the time of the Warnock Committee, after-all the embryo was, and remains, an ethically contested entity. Of course human embryos are human just as the sperm and eggs from which they are created are human. However as Harris points out to chase a biological basis for moral status is to become involved in a fruitless journey ever further upstream to the source of the gametes and beyond; perhaps inevitably, and absurdly, to include every cell of the human body. ${ }^{12}$ However a quite different perspective emerges if one considers that the concept of a human being is not merely a biological term but rather entails an ontological claim about moral status. What Warnock seemed to be grasping for is the idea that being human is a mark of a certain kind of community membership. With this thought in mind it would seem very plausible that the creation of a human embryo with the capacity to become a child might plausibly be taken to be the first step towards 
entry into the human community. In making these points I can immediately see how vulnerable they are to the kinds of critique that Harris has so eloquently advanced. At this point I shall say nothing more than to acknowledge that idea of the human community as a moral domain is an intuitive claim and to offer by way of support for its plausibility the observation that we know quite distinctly what we mean when we appeal to another's humanity. To appeal to another's humanity is not an appeal to their biology but to their humaneness, including such moral qualities as compassion, kindness, and concern. Conversely; when we describe someone as 'inhumane' we are not making an observation about their biological makeup but pointing to a moral deficit when certain moral qualities are expected. Admittedly we are still left with the problem as to whether mapping 'human being' to everything that is biologically human creates far too rich an ontology; but equally, and to my mind of greater concern, is Harris's preferred 'propositional' criterion of moral status which yields an ontology that is far too inclusive in one sense, yet far too lean, in another sense. To explain what I mean by the 'propositional criterion' we need to consider Harris's claims in more detail.

\section{Harris's test for persons.}

Harris's test for persons is developed in two parts; first he quotes with approval Locke's definition of person:

...to find wherein personal identity consists, we must consider what person stands for; which, I think, is a thinking intelligent Being, that has reason and reflection, and can consider it self as it self, the same thinking thing in different times and places. ${ }^{13}$

Harris approves of Locke's definition of person because for Harris, whilst some human 
beings are persons, no human is a person in virtue of their being biologically human, a point that is also implied in Locke's definition. One need only be a 'thinking intelligent Being' no matter how that is instantiated. Harris also approves of the flexibility of Locke's account. Since Locke's criteria are species non-specific they are compatible with the possibility of non-human persons. To go along with a popular science-fiction fantasy, the as-yet-to-be proven existence of extra-terrestrials may prove to be both alien creatures and alien persons. Closer to home, Locke's criteria entertain the possibility of terrestrial non-human persons, pursuing another popular idea which sees potential candidates amongst certain favoured species of primate and sea mammal. Furthermore, given Locke's emphasis on the abstract properties of thinking and intelligence it is possible, in principle, for a person to be neither human nor biological and could conceivably be a complex machine. ${ }^{14}$ This marks one of the more significant levels of abstraction and is demonstrative of how Locke's (and Harris's) approach not only allows the person to be dis-embodied but also abstracted from any kind of social context. It is following this line of reasoning that I would suggest that Harris's ontology of the person is too inclusive.

In addition to Locke's intelligent thinker Harris adds the valuing criterion. The valuing criterion consists of the capacity to value one's life, that is; to be in a position so that one is capable of forming a judgement as to the goodness or badness of one's existence. This is what I call the 'propositional criterion', that a person must be capable of holding certain propositions of a self-valuing kind, in their mind. So even though a would-be suicide may hold their life in negative value, they are no less a person, since to value negatively is to nevertheless have passed the requisite threshold. 
So according to Harris the pre-eminent moral being is the full-blown person, a being that has rationality, self-consciousness, an awareness of self-identity over time and the capacity to value its own life. This quickly developed proposal from Harris is interesting because it is an example of a radically underdeveloped idea that actually poses some problems for the general thesis. The problem is this; that without some quite detailed and further elaboration from Harris the idea that a thinking intelligent being does everything required to earn its moral status seems deeply problematic, if not implausible. The problem can be illustrated in a rather tongue-in-cheek way with reference to the popular British science fiction television series 'Doctor Who' which features the Doctor's infamous enemy the Daleks. ${ }^{15}$ The Daleks are an extra-terrestrial race of powerful mutants and bent on the complete subjugation of the universe, and their path to domination is characterised by an utter lack of pity, compassion or remorse for their cruel actions in the attempt to rid the Universe of all non-Dalek life. The point of this example is to show that though we have in the Dalek an extra-terrestrial example of a thinking intelligent being that may well meet the criteria for status as a person this is not sufficient to show that we are bound to respond to them as creatures worthy of the same 'concern, respect and protection, ${ }^{16}$ as we are to the rest of humanity. I don't think that there would be a dilemma, as Harris puts it, whether to have this particular alien creature for dinner in one sense or in the other sense of 'have'; we just wouldn't want to be anywhere near them! Of course Harris might respond that the Daleks and their ruthlessness are no different in kind from the common moral problems we face with other human beings who display utter contempt for their fellow humans on the mere and arbitrary basis of race, creed or colour. History and indeed contemporary events can furnish too many examples 
of bad people, but one might argue that they can be held to account and treated as equals under the law. However this is not the point I am making here with regard to alien creatures like the Daleks. The point can be better illustrated by a rather cryptic remark made by the philosopher Wittgenstein who states: 'If a lion could talk we could not understand him'. ${ }^{17}$ Wittgenstein's remark is part of his general critique of theories about meaning and language, but since meaning and language are part of a culture of 'use', deeply embedded, rule-governed behaviours it is also applicable to the human culture of values and morality; at an earlier point in the same book he says:

Suppose you came as an explorer into an unknown country with a language quite strange to you. In what circumstances would you say that the people there gave orders, understood them, obeyed them, rebelled against them and so on?

The common behaviour of mankind is the system of reference by means of which we interpret an unknown language. ${ }^{18}$

The point that Wittgenstein is making is that the very possibility of making sense of the unknown language, the possibility of achieving a translation, hinges upon the fact that humanity shares a 'form of life' a common grounding in shared normative ideals without which we cannot begin to make sense of the alien life whether it be Daleks or lions.

One could of course imagine an anthropologist spending time observing Dalek culture and offering an account of its richness and variety. What would we need to learn about their culture in order to be persuaded that there was the possibility of a moral dialogue with them, of persuading them that they ought to respect us as we aspire to respect each other? 
One of the problems with the account of moral worth implied by the arguments set out in TVOL is that they fail to acknowledge sufficiently that whilst some humans may be judged as lacking the requisite capacities to be moral agents it does not follow that humans who lack the capacity of moral agency also lack moral worth. The specific implications ought to be obvious but I will spell these out with regard to issues at the beginning of life.

Harris's book was published at a time of wide debate over the ethics of IVF and embryo research. The person argument has very specific implications for IVF, embryo research, and for abortion and neonatal care also. Harris writes, that on the basis of his argument: ...the prospect of concluding that the embryo shares the rights and protections of normal adult human beings is vanishingly small.

It will also be a consequence of the arguments developed here that since neonates and very young children are not capable of wishing to live, it will be no more wrong to kill them, side effects apart, than to kill other creatures of comparable capacities like dogs and sheep. ${ }^{19}$

It is important to note here that Harris does not argue that it will be no wrong at all to kill neonates or very young children but rather, and this by implication not his own elaboration, that it would be a very minimal wrong. Harris offers few grounds for understanding the nature of the wrong, which seems remarkable considering the implications of the claim, perhaps the wrong of inflicting pain on a sentient creature or the wrong of thwarting the preferences of doting parents? But since he is suggesting a shocking and quite repulsive conclusion that neonates and young children may be killed almost with impunity it might be expected that he would take some time to elaborate on 
the point. What he does offer is a lowering of the threshold of 'significance' within a margin of safety:

The problem is that we not only want reliable criteria for personhood, but we want detectable evidence of personhood. Here matters are not so simple, and we should err on the side of caution and assume, in the case of the sorts of creatures that we know to be normally capable of developing self consciousness, namely human creatures, that they are persons at some safe time prior to the manifestation of the symptoms of personhood. I do not have a set view as to when an appropriate point would be, but I do not think it plausible to regard the emerging human individual, for example, as possessing the relevant capacities at any time while in utero or during the neonatal period. ${ }^{20}$

I find this 'margin of error' clause rather perplexing here without some more concrete account of what might count as 'detectable evidence'. Elsewhere Harris is clear that a person must be capable of holding certain propositions about themselves and ideally giving evidence to this through spoken language, what I have called the 'propositional criterion'. I would suggest that this is a failure of Harris to fulfill a basic requirement of applied moral philosophy; to engage in reflective equilibrium and moderate the theoretical implications of adopting a philosophical approach in the light of established moral intuitions. This I would suggest is an example of Harris's too lean an ontology, excluding what we have good reason to presume is within the moral domain.

The development of medical technologies deployed at the beginning of human life has made the moral landscape more and not less complex. Harris's persons approach has potential implications for policy and practice that few would tolerate. The smiling and 
frowning fetus now so dramatically revealed by the latest $4 \mathrm{D}$ ultrasound for example provides an insight into the life of the fetus that is morally challenging in a similar way that research into neonatal pain has been. What we see suggests that the fetus, in its expressions of satisfaction and discomfort, already possesses the basis of its participation in the moral community. For Harris this is no doubt anthropocentricism of the worst kind. However I do not believe that this response is merely the 'soggy sentimentality classically evoked by proximity to dependent sentient creatures, like puppies ${ }^{21}$, the fact that medical technology, and micro-surgical techniques are increasingly applied to the fetus in utero means that we do recognize that the fetus is a patient and not merely a temporary organ of the woman within whose body it is growing.

Turning briefly to Harris's critique of the moral status of the embryo I want to explore why we might also be reluctant to follow Harris's arguments to their logical conclusion in this context. Here I would venture to claim that Harris is insufficiently aware of, or merely reluctant to consider what Eva Kittay calls the 'ethics of philosophizing, ${ }^{22}$ What Kittay means by this is the failure to consider the full practical implications of philosophical theorizing. Perhaps I am being too harsh on Harris here; he does seem to be aware of the potential harm of treating neonates and young children as non-persons though it seems only a begrudging nod to wider human sensibilities. Harris is generally sanguine about the moral implications of his account of the person. He believes we ought to make the shift from the anthropocentric person to the abstracted person and in doing so be relieved of the burden of some seemingly profound moral problems. However the growing body of empirical evidence regarding the social and ethical aspects of reproductive and regenerative medicine research shows that the issues are complex and 
that genuine moral concern will not be alleviated by an abstract account of personhood. Macleod and Baylis, ${ }^{23}$ Haimes and Taylor ${ }^{24}$ and others have shown that women who face the challenging decisions around artificial reproductive therapy (ART), and more recently the close connection ART has with regenerative medicine research, walk a complex moral path. The researcher de Lacey comments that the "process of determining an outcome for frozen embryos is a complex human experience, the depth of which has not yet been fully described'. ${ }^{25}$

The dilemmas these women face are often associated with the choices they have or are about to make with respect to determining the fate of one or more of their eggs or embryos. The women who seek ART and at the same time agree to participate in research are made fully cognizant of the implications for the embryos; specifically that not all embryos will be given a chance of life. However this does not mean that they are unconcerned as to the fate of those embryos.

Agreeing to donate an embryo, or even an egg, to research means that one potential source of a viable foetus, and potentially a child, is denied them. Haimes and Taylor's interviews with women have shown that they are often pre-occupied with what is referred to as the "third embryo" 26 , the good embryo that was not implanted because it was donated to research. Haimes quite nicely captures the multiple demands made of women in this context as the feat of 'juggling on a roller-coaster'. ${ }^{27}$ The concern that women express for the fate of the 'third embryo' arises because they do not see it merely as 'spare' tissue but as an entity that has already taken the first step into the moral community; an entity with a certain kind of potentiality. 
Space does not permit a more detailed analysis of the contribution that this important empirical work is making to our understanding of the complex ethical issues in the context of ART, embryo selection, storage and donation. It does indicate the need for ethical analysis to be empirically informed, nuanced and subtle.

Harris is of course dismissive of the concept of potentiality and has argued on many occasions that because a thing merely has the potential to become $\mathrm{X}$ this is not a reason for treating it as though it already were X. However I think this overstates how potentiality may be understood in these contexts. I certainly agree with Harris that it is wrong to treat an embryo with all the rights and respect owed to fully fledged human beings. However this does not mean that no consideration is owed to the embryo for the potentiality it does have. Women undergoing ART, as Haimes's 'juggling' metaphor captures, are constantly trying to reconcile the different decisions they do make with their desire to maximise the chances of at least one of those embryos developing into a child.

I would argue that Harris also recognises that the potential of an embryo does have some moral pull, since he sets out the basic arguments in TVOL, developed much more in his later work that it would be morally wrong to waste the potential an embryo has to be converted into a good from which others may benefit. What he has in mind are the potential benefits to others arising from what is now termed 'regenerative medicine', the application of embryonic stem-cells, though it must be remembered that at the time of writing the potential for any actual benefit to an individual was highly theoretical. It might be argued that what Harris means here is that the moral pull of the embryo's potential is derived from the potential benefit it could have for a fully fledged human recipient of stem-cell therapy. However another of Harris's arguments makes this less 
clear. Considering the issue of enhancement, first outlined in TVOL, and also developed further in later work, he argues that if we are to procreate then there is a moral obligation to produce the best children possible. One route to this end certainly includes the genetic selection of embryos but also the genetic modification of embryos, where this might lead to an enhancement of certain valued traits in the resulting human being. It seems reasonable to ask to what is this obligation owed? To the future person certainly, but that future person is merely the result of the potential that the embryo now has. Our moral obligation to treat the embryo in certain ways and not in others is because of the potential the embryo has to become the future 'enhanced' person. While recognising the potentiality of an embryo does not commit us to treating the embryo as if it were a full human being it is surely, even in Harris's terms, owed some form of moral consideration?

\section{Valuing and attachment.}

The central thesis of TVOL is that ethics revolves around the concept of the person, a class of entities of which only some human beings are members. The defining feature of a person is a capacity for self-valuing. Hence a morally significant entity is that which is, minimally, capable of holding a value position with regard to itself.

Harris tells us:

I believe those rather simple, even formal features of what it takes to be a person - that persons are beings capable of valuing their own lives - can tell us a good deal about what it is to treat some-one as a person. ${ }^{28}$

It is a frustrating feature of TVOL that Harris gives no account of how such a valuing individual evolves. I believe that there are accounts of how a human being 
gains a foothold within the moral community which are necessarily embodied and human. It is impossible to develop these ideas in any detail here.

A sense of how a self-valuer evolves can be gained by reflecting on human development. A feature of human offspring is their prolonged dependency as they develop their intellectual and communicative capacities. That adults are usually enchanted by the helplessness of a baby is no doubt an evolutionary trait necessary for survival. But the nurturing of a child is also a time of rich reciprocal communication with much being expressed behaviourally and non-verbally. We have certainly not exhausted all there is to know about this aspect of human life. To ignore the context in which individuals evolve and are nurtured into adulthood is to ignore an important aspect of human moral evolution.

When Wittgenstein states: 'the human face is the best picture of the human soul'29 I take him not to be making a theological claim but rather saying that the human face, and for that matter the human body, is capable of showing, through its demeanour and through facial expression, spontaneously recognised by others, a recognition that is partly constitutive of identity. In claiming that it is only in virtue of being a self-valuer that we are able to recognise the value of others, Harris reverses the direction of the relationship between the other and the self, a point noted by Adam Smith:

Were it possible that a human creature could grow up in some solitary place without any communication with his own species, he could no more think of his character, of the propriety or demit of his sentiments and conduct, of the beauty or deformity of his mind, than of the beauty of his 
own face... Bring him into society and he is immediately provided with the mirror which he wanted before. ${ }^{30}$

Smith is cited by Laurence Thomas, whose brief discussion of moral psychology, offers an account of the evolution of the self-valuer in the context of human development. ${ }^{31}$ Thomas claims that it is in the context of human parental nurturing that the individual develops a sense of both self-worth and the worth of others:

[...] what is involved in bringing it about that a child has a sense of intrinsic self-worth is having the experience of being treated in the appropriate way by those who themselves have worth, and so have regard for themselves.

From the moral point of view, the intrinsic self-worth that parental love bestows upon the child is what underwrites the child's sense of how he or she should be treated by others. ${ }^{32}$

Of course I do not wish to claim too much on the basis of what can only be discussed briefly here. I merely suggest that the experience of being valued and hence a sense of self-value is quite plausibly prior to the linguistic abilities needed to conceptualise and communicate this status, the basis from which we will stake our claims and make our moral arguments. By comparison to this richer anthropocentric account Harris's person appears as quite a thin shade.

I suggest that something like the Thomas account comes nearer to the truth of the matter about the background conditions from which a self-valuer evolves. It also offers a picture which is coherent with the idea that to be human is to be part of a 
moral community. Harris's person, as I have argued, is abstract, unencumbered by the ties of a body, of relations with others within a human community. I do not wish to make too much of a possible mind/body dualist reading of Harris but severely underestimates the embodied nature of the person. I suggest that 'person' is necessarily the embodied human person. Wittgenstein's remark suggests that the body is not merely a contingent carrier of the person but shows the person. To see a smile, a wince, a frown in the face of another is to see their satisfaction or discomfort. The expressive and embodied individual is the starting point for moral significance.

The conceptualization of the person as embodied is a familiar one in phenomenology. Emmanuel Levinas's ethics reflects a central interest of phenomenology; the particular salience of encountering another person, what Levinas calls the 'Other'. ${ }^{33}$ For Levinas the most salient aspect of the experience of the 'Other' is the face of the Other, since it is the face of the Other which intrudes upon one's own being with a moral force. For Levinas the Other is an intrusion into one's own being, experienced not as a presence or an object of knowledge but as a moral demand not to harm, a moral obligation. The Levinas 'face' is not a particular face but an abstraction. The face is to be understood as a challenge, it is the vulnerability of the Other that undermines one's own ambitions and ends because it presents us with an obligation, a duty.

The proximity of the other is the face's meaning, [...] Prior to any particular expression and beneath all particular expressions, there is nakedness and destitution of expression as such, that is to say extreme exposure, defencelessness, vulnerability itself. This extreme exposure - prior to any human aim - is like a shot "at point bank range. ${ }^{34}$

What seems apposite to the present discussion is the idea that recognising the vulnerability of another is also central to human moral experience. For Harris an 
individual only gains intrinsic value once it can assert its 'rights and interests' (ideally) through spoken propositions.

I am a gradualist, a position rejected by Harris because personhood for Harris is a "threshold concept" and "proximity to the threshold is unimportant compared with the importance of crossing it." ${ }^{35}$ However what I hope I have at least introduced is that Harris's account of the person is too thinly drawn, too abstract, and too remote from the human domain.

\section{Concluding thoughts.}

We should be open-minded to the possibility that some as yet un-encountered non-humans might also be moral agents. This seems most feasible in the context of those entities, like for example the 'higher' mammals that live in close and nurturing family groups. However despite the fascinating observations made of chimpanzees, and elephants, and various sea-mammals I am unconvinced that we have discovered any strong candidates for moral agents within the (non-human) animal kingdom encountered this far. What this emphatically does not show is that there is reason to disregard the welfare and interests of non-human animals. We should be kind to puppies, but Daniel and his lion not withstanding, unless we can discover some deeply shared moral reciprocity between humans and other 'beings' then we, human beings, will remain the only moral agents, and as I would prefer, the only persons.

\section{References.}

\footnotetext{
${ }^{1}$ John Harris, The Value of Life (London: Routledge and Kegan Paul, (1985)

${ }^{2}$ Harris, The Value of Life, p. 9.
} 
${ }^{3}$ Singer P. Rethinking Life and Death: The collapse of our traditional ethics. New York, St Martin's Press. (1994)

${ }^{4}$ Tooley M. Abortion and Infanticide. New York, Oxford University Press. (1984)

${ }^{5}$ McMahan J. The ethics of killing: Problems at the margins of life. Oxford, Oxford University Press (2003).

${ }^{6}$ Department of Health \& Social Security. Report of the Committee of inquiry into Human fertilisation and Embryology. (1984) HMSO, London.

7 Mary Warnock, "In vitro fertilisation: The ethical issues (II)," The Philosophical Quarterly, 33:132 (1983), pp. 238-249, p. 241.

${ }^{8}$ See for example John Harris, "In vitro fertilisation: The ethical issues (I)," The Philosophical Quarterly, 33:132 (1983), pp. 217-237; and John Harris, "The Concept of the Person and the Value of Life," Kennedy Institute of Ethics Journal, 9:4 (1999), pp 293-308.

${ }^{9}$ Grobstein C From Chance to Purpose. Addison Wesley, London. 1981 p. 89.

10 Though now the term 'embryo' has undergone further re-definition and refers exclusively to the preimplantation embryo less than 14 days old.

${ }^{11}$ Harris, "In vitro fertilisation: The ethical issues (I)," p. 224.

12 Devolder K, Ward C.M. Rescuing human embryonic stem cell research: the possibility of embryo reconstitution after stem cell derivation. Metaphilosophy. 2007. 38; 2-3; 245-263.

13 John Locke, An essay Concerning Human Understanding (London: Everyman, 1976), p. 162.

${ }^{14}$ Harris, "The Concept of the Person and the Value of Life," p. 303.

${ }^{15}$ Daleks were conceived by science-fiction writer Terry Nation and first appeared in the 1963 on BBC T.V.

${ }^{16}$ Harris TVOL p. 9

${ }^{17}$ Ludwig Wittgenstein, Philosophical Investigations (Trans. Gertrude E.M. Anscombe) (Oxford: Basil Blackwell, 1958), p.233.

${ }^{18}$ Ludwig Wittgenstein, Philosophical Investigations (Trans. Gertrude E.M. Anscombe) (Oxford: Basil Blackwell, 1958)

${ }^{19}$ Harris, "In vitro fertilisation: The ethical issues (I)," p. 226.

${ }^{20}$ Harris, "The Concept of the Person and the Value of Life," pp. 304-305.

${ }^{21}$ Harris, The Value of Life, p. 13.

22 Kittay E. Ideal Theory Bioethics and Cognitive Disabilities. In Lindemann H. Verlerk M. Urban Walker M. (2009) Naturalised Bioethics. 218-237. Cambridge University Press.

${ }^{23}$ C. McLeod \& F. Baylis. Donating Fresh Versus Frozen Embryos to Stem Cell Research: in Whose Interests? Bioethics 2007; 21: 465-477.

${ }^{24}$ Haimes E, Taylor K. Researching the Relationships between Tissue Providers, Clinicians, and Stem Cell Scientists. Cell Stem Cell 2011, 8(6), 613-615.

${ }^{25}$ S. de Lacey. Decisions for the Fate of Frozen Embryos, Hum Reprod 2007; 22: 1751-1758: p. 1752.

${ }^{26}$ Haimes E, Taylor K. The contributions of empirical evidence to socio-ethical debates on fresh embryo donation for human embryonic stem cell research. Bioethics Volume 25 Number 62011 pp 334-341

${ }^{27}$ Haimes E. Juggling on a rollercoaster? Gains, loss and uncertainties in IVF patients' accounts of volunteering for a U.K. 'egg sharing for research' scheme. Social Science and Medicine 2013, 86, 45-51.

${ }^{28}$ Harris, TOVL, p. 16.

${ }^{29}$ Ludwig Wittgenstein, Philosophical Investigations (Trans. Gertrude E.M. Anscombe) (Oxford: Basil Blackwell, 1958), II.iv.178.

${ }^{30}$ Adam Smith, A Theory of Moral Sentiments (Indianapolis: Liberty Classics, 1976), III.i.3.

${ }^{31}$ Laurence Thomas, "Moral Psychology," The Blackwell Guide to Ethical Theory, ed. Hugh LaFollette (Oxford: Blackwell, 2000), pp. 149-162.

32 Ibid., p. 152.

33 Emmanuel Levinas, "Ethics as first philosophy," The Levinas Reader, ed. Sean Hand, (Oxford: Blackwell Publications, 1989), pp. 75-87. 
${ }^{34}$ Ibid., p. 83.

${ }^{35}$ Harris, "The Concept of the Person and the Value of Life," p. 300.

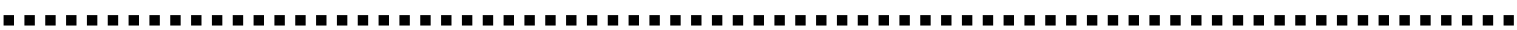

